of the capacity and flexibility needed to respond immediately to the rapidly changing dynamic of infectious diseases such as $\mathrm{H} 5 \mathrm{N1}$, enterovirus 71 or artemisininresistant malaria, and can make results available in real time. Such an approach is impossible when the work requires individuals to fly in and out and to analyse samples in another country.

\section{SMALL BUT POWERFUL}

There are other great examples of long-term research partnerships between national and international organizations, but they are all too few. These infrastructures are easier to build than many believe - you need only a small group of committed people, a shared vision and ethos, flexible funding that encourages local decision-making, and a focus on excellence. There can be great power in such small institutions - which may need as little as a few hundred thousand dollars a year to operate - if only we made better use of them (G. T. Keusch and C. A. Medlin Nature 422, 561-562; 2003).

Because our research unit is based in the region where the story is unfolding, we can appreciate the social issues that can stymie even the best scientific endeavour. For instance, small-scale backyard poultry farms (often family farms with mixed chickens, ducks and pigs) remain a crucial livelihood and the main source of protein for many households in rural Asia. Because no adequate compensation schemes have been developed to encourage reporting of sick poultry and livestock, the usual responses are to cull all local poultry and apportion blame. Such activities can ruin small farmers and their families.

There is now a window of opportunity to build global scientific capacity before another crisis - such as a new pandemic - hits. This means collaborating with the people who share a vested interest in using the money efficiently and effectively to prevent outbreaks and address daily public-health and clinical issues in their own countries. After living in Vietnam for more than 16 years and raising my family here, I can understand the feeling of urgency. Everyone I work with who sees chickens each day on their way to work, hears about local outbreaks in the news or treats patients is united in the effort to stay one step ahead of H5N1 and other potentially deadly outbreaks. We must share the available knowledge and the tools to make it possible an undertaking that will require us to shift the centre of gravity for such research to where the needs are greatest..

Jeremy Farrar is at the Hospital for Tropical Diseases, Wellcome Trust Major Overseas Programme, Oxford University Clinical Research Unit, Ho Chi Minh City, Vietnam. e-mail:jfarrar@oucru.org

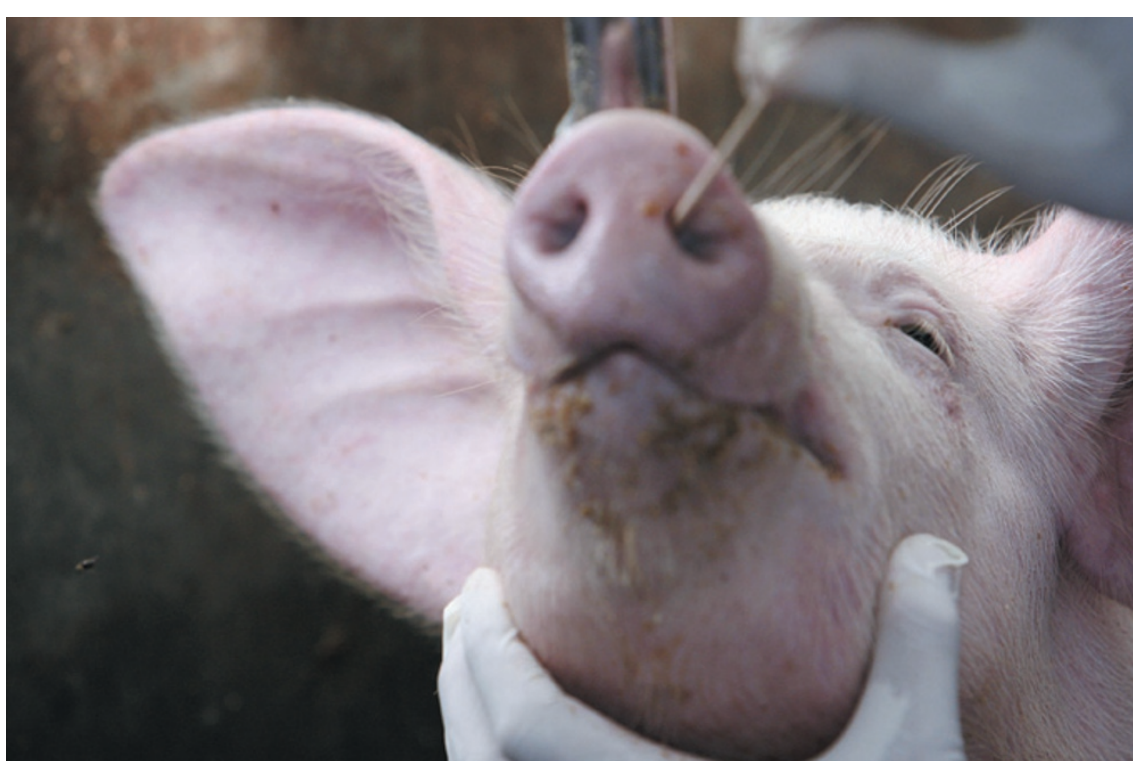

A swab sample is taken from a pig in the village of Yeh Kuning, Bali, to test for H5N1 influenza.

\title{
How to track a flu virus
}

\section{Four experts pinpoint ways to improve monitoring of H5N1 avian influenza in the field.}

\section{YIGUAN}

\section{Monitor outbreaks in domestic ducks}

\section{Joint Influenza Research Centre, Shantou University Medical College and University of Hong Kong, China}

The H5N1 influenza outbreak in Asia is unprecedented: never before has a highly pathogenic avian influenza virus prevailed for so long, spread to so many countries or generated so many genetic variants. Why? Partly because of its persistence in domestic ducks.

In parts of southeast Asia such as China and Vietnam, H5N1 has remained endemic. Elsewhere, small outbreaks last for a very short time. The major difference between these regions is their domestic duck populations - more than $70 \%$ of the world's ducks are raised where $\mathrm{H} 5 \mathrm{~N} 1$ is endemic.

In our 12-year surveillance, more than $65 \%$ of the $\mathrm{H} 5 \mathrm{~N} 1$ viruses my colleagues and I isolated were from domestic ducks. Asymptomatic ducks could shed high concentrations of the virus for several days. Although the $\mathrm{H} 5 \mathrm{~N} 1$ virus resides in domestic ducks, it can interact with other subtypes of influenza, for which these birds are part of the natural reservoir. This mixing creates novel variants, which may trigger outbreaks and dissemination of the virus. Domestic ducks probably shelter the $\mathrm{H} 5 \mathrm{~N} 1$ virus during the summer and then seed the next outbreak, which, in bird populations, usually peaks during the winter.

At present, surveillance of duck populations is limited. Eradication of H5N1 will require more active surveillance in affected areas, along with widespread vaccination of duck populations, segregation of poultry species and local moratoriums on poultry production when outbreaks occur.

RICHARD WEBBY

\section{Improve surveillance of pigs}

Department of Infectious Diseases, St Jude Children's Research Hospital, Memphis, Tennessee

One major problem with H5N1 surveillance is the lack of coordinated monitoring in pigs. Although $\mathrm{H} 5 \mathrm{~N} 1$ is considered to be avian flu, the same mutations that 
allow the virus to be transmitted between ferrets could make it more contagious among both humans and pigs. Any virus that circulates in pigs can be a risk to humans just look at the furore over the $2009 \mathrm{H} 1 \mathrm{~N} 1$ pandemic, which probably originated in pigs. And, because pigs can harbour multiple strains of the influenza virus, they are good incubators for mutants - including those that might make $\mathrm{H} 5 \mathrm{~N} 1$, for example, more contagious.

In most countries where pigs are farmed, one only has to look for swine influenza viruses to find them. Systematic surveillance in pigs is conducted in some countries, but in other parts of the world there is none. We must encourage all countries with large pig populations to perform systematic surveillance and to report what they find.

My colleagues and I have conducted surveillance of US farms for the past few years, sampling healthy pigs once a month to get a baseline of influenza activity so that we can act quickly at the first hints of unusual activity. We've found that $2-4 \%$ of all seemingly healthy animals harbour some type of influenza virus.

We, along with others in the swine-influenza group of the OIE-FAO Network of Expertise on Animal Influenza (OFFLU), deposit our data in a public database. Swine-influenza surveillance done now is scattered - among universities, industry and government agencies. A good first step, as the OFFLU group urges, is to begin to coordinate that activity with measures such as the creation of a centralized database.

\section{ILARIA CAPUA Restore ties lost in the Arab Spring}

Director, International Reference Laboratory for Avian Influenza and Newcastle Disease, Veterinary Public Health Institute, Legnaro, Italy

Over the past six years, my lab has developed collaborations with veterinary authorities in several African and Middle Eastern countries to conduct surveillance of avian influenza. The Arab Spring has transformed society in some of these countries, but it has negatively influenced our efforts to monitor $\mathrm{H} 5 \mathrm{~N} 1$ in nature.

In Egypt, outbreaks in poultry are

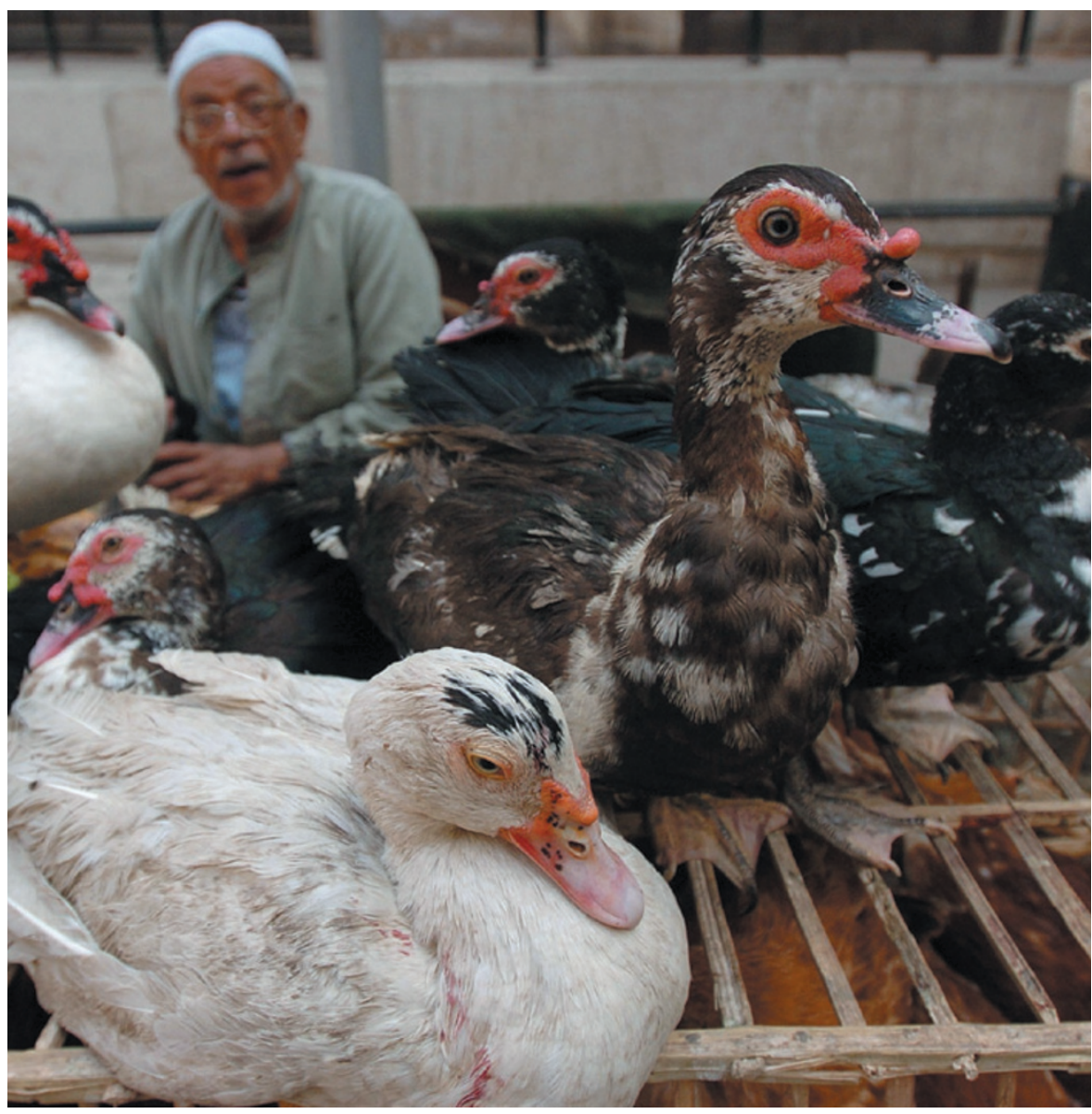

A man sells fowl at a market in Cairo. In Egypt, H5N1 was first observed in 2006 in domestic poultry. widespread, and 58 people have so far died of the disease. The country had begun developing a system to combat $\mathrm{H} 5 \mathrm{~N} 1$ with the aid of international agencies and donors. The system was not perfect, but it was the result of years of work to build capacity and train personnel. Since the social unrest began, things have changed. Some of our local contacts have moved to other positions, leaving gaps in expertise.

At present, we are working mainly with local universities and industry. On average, we can analyse viral genomes within 4-6 months after they are isolated from the field - a delay that could easily nullify the benefits of monitoring a potentially pandemic virus while it is still in the animal reservoir.

We recently met with newly appointed veterinary officials in Egypt and discussed collaboration and ways forward. We are confident that improved surveillance will be one of the positive outcomes of these discussions. The support of international organizations is crucial to the success of such efforts.

\section{JONASWALDENSTRÖM Learn more about the role of wild birds}

School of Natural Sciences, Linnaeus University, Kalmar, Sweden

Migrating birds can be infected with $\mathrm{H} 5 \mathrm{~N} 1$ and could potentially spread the virus along migratory flyways. Despite intense, active surveillance, we still know frustratingly little about how $\mathrm{H} 5 \mathrm{~N} 1$ is transmitted in the environment and between wild and domestic birds.

My colleagues and I have screened samples from 30,000 European waterfowl without finding $\mathrm{H} 5 \mathrm{~N} 1$ - or any other highly pathogenic influenza virus during or after the H5N1 outbreak in this population. Haphazard sampling and poor logistics may contribute to poor detection rates, or the virus simply may not be in the population when we search for it.

We must provide greater resource support for areas at high risk of $\mathrm{H} 5 \mathrm{~N} 1$ and develop better tools for detecting the virus in wild birds so that we can better assess the role of these populations in virus perpetuation, on local and global scales. Surveillance programmes should be complemented with more-targeted studies that address key questions in H5N1 epidemiology, such as how virus transmission occurs at the interface between domestic poultry and wild birds. 